\title{
Performance measurement systems, competitive priorities, and advanced manufacturing technology
} Some evidence from the aeronautical sector

\author{
Macarena Sacristán Díaz \\ Dpto de Economía Financiera y Dirección de Operaciones, \\ Universidad de Sevilla, Sevilla, Spain \\ María José Álvarez Gil \\ Dpto de Economía de la Empresa, \\ Universidad Carlos III de Madrid, Madrid, Spain, and \\ José A. Dominguez Machuca \\ Dpto de Economia Financiera y Dirección de Operaciones, \\ Universidad de Sevilla, Sevilla, Spain
}

\begin{abstract}
Purpose - When acquiring advanced manufacturing technologies (AMT), the greatest caution should be taken regarding the performance measurement system to be used: the decision regarding new investments should not be conditioned by the excessive use of financial indicators to the detriment of the strategic objectives that motivated the investments. It is intended to analyze the aeronautical sector, for which the purchase of AMT is qualifying criteria, with two intentions: first, to identify the performance measurement systems that are used, and second, to test their correspondence with the objectives that motivated the investments.

Design/methodology/approach - A survey of the 20 plants in the population was conducted via a postal questionnaire plus a structured interview. The unit of analysis has been maintained through the triangulation of data sources.

Findings - The findings suggest that both financial and non-financial indicators are used, with the latter gaining predominance over the former on some occasions, even though there is no clear correspondence between strategy and the measurement of performance. In the light of the findings, the question of what inspires a company's performance measurement system is still open, especially in those cases where there is no explicit strategy. With regard to practical implications, what seems to be indispensable is an improvement in the determination of the critical variables that should be used to measure performance. Research limitations/implications - Being valuable for academics and practitioners, this contribution relies, rather, on the possibility of a logical extrapolation to circumstances where the findings might apply, and researchers can judge whether the particular findings would be valid.

Originality/value - Provides new evidence on the adaptation of the make-up and combination of the type of performance measures currently used by plants in the aeronautical industry, one of the sectors in which technological innovation is of the utmost importance.
\end{abstract}

Keywords Advanced manufacturing technologies, Operations management, Performance measures, Aircraft industry, Spain

Paper type Research paper 


\section{Introduction}

When monitoring the results of investments made in advanced manufacturing technologies (AMT) it is dangerous to focus solely on costs, as it is possible that the system used to assess performance might lead managers to ignore other strategic objectives (Brown and Laverick, 1994; Ghalayini and Noble, 1996; Bititci et al., 2001; Karsak and Tolga, 2001; Morgan and Daniels, 2001). Over the last ten years many authors have suggested that in the AMT performance measurement systems, financial and cost indicators should be complemented by non-financial measurement tests related to quality, delivery and flexibility, with the integration of the different business areas being encouraged and the management's strategic objectives being reflected (Kaplan and Norton, 1992; Bititci et al., 1997; MacDougall and Pike, 2003).

Empirical data on a change in the types of measures employed, that is, the adaptation of the make up and combination of the types of performance measures, is contradictory (Bhimani, 1994; Tayles and Drury, 1994; Abernethy and Lillis, 1995; Perera et al., 1997; De Toni and Tonchia, 2001). The primary objective of this study is to provide new evidence on this issue based on an analysis of the aeronautical sector, in which the acquisition of these technologies is imperative, not only for differentiation in the market (order winning criteria), but also, to put it bluntly, for survival (qualifying criteria). Our second objective is aimed at testing to see whether there is a correspondence or "fit" between said measures and areas of performance measurement, and the objectives that motivated the investments, as is recommended in theory on the subject (Brown and Laverick, 1994; Small and Chen, 1995; Pawar and Driva, 1999).

Within the aeronautical sector we have focused on a geographical area of Europe, Andalusia, where large and medium, small and very small companies can be found, and where 40 percent of companies have a workforce of under 50 employees. Several of the Spanish national aeronautical company's manufacturing plants can be found in the Andalusian aeronautical industry. The company in question, CASA, joined the Airbus Consortium in 1971 and has belonged to EADS (the European Aeronautic, Defence and Space Company) since it was formed in 2000. There are also a number of SME ancillary firms in the sector who supply both other Spanish aeronautical companies, including CASA, and foreign companies. We believed it was very important to include the CASA-group factories in the analysis; it was a requirement if the whole population was to be studied and at the same time allowed us to compare companies of widely different sizes. The fact that several factories included in the study belonged to the same group does not affect the results, as CASA had still not joined EADS when we conducted our research. Apart from this, the heads of the engineering departments we interviewed stated that, although they have to have their final choices approved by head office, the group's factories all draw up their own separate technology strategies, and can not only choose which equipment they are to purchase, but also conduct their own independent assessment of the equipment.

The next section of this paper describes the state of the art and sets out the research questions and hypotheses. This is followed by the sections which describe the methods and wherein the results are analyzed and discussed. The final section of the paper presents the conclusions drawn and proposes some possible future research avenues. 


\section{State-of-the-art and research questions}

Ghalayini and Noble (1996) differentiate between two stages of performance measurement in literature. The first stage, which they set between the 1880s and the 1980s, puts the emphasis on financial measures, such as profit, returns on investment, and productivity. The second stage, which according to them commences at the end of the 1980s, is a result of the changes that world markets underwent, including the implementation of new manufacturing technologies, and new production management philosophies. These changes have shown up the limitations of traditional performance measurement systems, as well as the need for new systems to be developed. Waggoner et al. (1999) have identified as many as six different approaches on the basis of which the set of measures or indicators available to a company are devised: engineering, systems, management accounting, statistical, consumer marketing and conformance to specifications.

A study of these works reveals the advisability of supplementing conventional financial indicators with other indicators which are better suited to rating the performance of the manufacturing process on the basis of company's competitive priorities, such as the achievement of the levels of quality agreed with the customer, the reliability of delivery, and/or flexibility. The original idea was established more than a decade ago by Kaplan and Norton (1992) with their balanced scorecard. According to this, the critical business areas should not compete with one another, but rather they require the balanced use of both financial and operational measures for their integrated development.

This procedure seems to be indispensable if any consistency is to be maintained in the decisions the company takes to develop the structure before the strategy is implemented and to get on track towards achieving its organizational objectives. As such, in the same way that the importance of taking the intangible factors into consideration is highlighted when technologies are being assessed and selected (the increase in the plant's productive capacity, greater customer satisfaction, shorter delivery times, faster development of new products, the ability to have a bearing on market characteristics in the long term, and so on) (for example: Kaplan, 1986; Meredith and Suresh, 1986; Shank and Govindarajan, 1992; Soni et al., 1992; Shank, 1996; Kakati, 1997; Chiadamrong and O'Brien, 1999; Del Sol and Ghemawat, 1999; and Talluri and Yoon, 2000; amongst others), it is evident that the same factors will have to be taken into consideration when the result gained from the new equipment and activities is measured. The determination of the critical variables that should be used to measure system performance therefore becomes a key issue (Brown and Laverick, 1994; Small and Chen, 1995; Pawar and Driva, 1999); bearing in mind that it is virtually impossible to provide a generic list of measures that can be applied to all manufacturing firms, or, at the very least, all the firms in the same sector.

In effect, the empirical evidence relating to systems that have been implemented by AMT-acquiring companies of different sizes, from different countries and in a variety of industrial sectors, is contradictory. There are cases where financial indicators alone are applied (Bhimani, 1994) and other situations where great emphasis is put on the use of incorporating other indicators as well, such as those found in Abernethy and Lillis (1995), Westra et al. (1996), and Perera et al. (1997).

Given that there is far from conclusive empirical date regarding both the choice of measurement system and the changes that are taking place for the system to be 
redefined, our first objective aims at providing new empirical evidence that might help consolidate theory in this regard. When putting forward this hypothesis we have nevertheless accepted the premise that there are differences in the degree of importance given to each of a company's functional areas when determining the performance measures that allow AMT investments to be monitored, as was indicated in the majority of the above-cited works. The first hypothesis we put forward is therefore as follows:

H1. The companies studied give different degrees of importance to their different functional areas (technical-operational, commercial, accounts-finances, et al.) for the process of measuring the performance of their investments in AMT, and use performance indicators that are representative of each area.

In other respects, according to some authors, performance measurement systems should in themselves provide an insight into strategy: "The choice of a given measurement criterion should in itself be a reflection of the management's strategic goals" (Leong and Ward, 1995). The means that performance measurement should serve both for the process of drawing up strategy and for knowing what the strategy entails; with regard to the former, because it provides information regarding the efficacy of strategic decisions and suggests areas where corrections can be made, and, with respect to the latter, because a good measurement system would reflect the competitive priorities of the business unit. Otherwise, if there were a change in strategy, the old performance measures - which would become obsolete - would be an obstacle to steps being taken to achieving the new objectives of the organisation (Keegan et al., 1989), bearing in mind that performance measurements are an integral part of the business planning and monitoring process. This standpoint is backed up by the recognition that these measures could affect management behaviour (Neely et al., 1994; Daniels and Burns, 1997).

In keeping with the aforegoing, our second working hypothesis is directed at determining whether there is a correspondence, or fit, between the performance measures used and the objectives that are being pursued through the acquisition of AMT, and reads as follows:

H2. In the companies analysed, there is a correspondence between the objectives being pursued by investment in a specific type of AMT and the indicators used to measure its performance.

Given that different categories of AMT exist, which implies that each is acquired according to the strategic objective pursued, this second hypothesis could be applied as often as required in order to test the aforementioned degree of fit for each investment in each category: design, manufacturing and planning.

Finally, since most of the plants in the population we studied were SMEs, and it is a known fact that the lack of a suitable planning process is a weak point of small companies in general terms, we were led to consider company size as a contingency factor to the possibility of there being a fit between the objectives of investments and the indicators used to monitor their performance. This reasoning completes the theoretical relationships that it is intended to test - which can be seen in Figure 1 - and lead us to our third working hypothesis: 
H3. The organizational size of the companies in our population significantly conditions the correspondence between the competitive priorities that motivate the investments, and the performance indicators used to monitor them.

\section{Methodology}

Encouraged by the recommendations on the use of questionnaires or surveys to develop operations management (Buffa, 1980; Chase, 1980; Swamidass, 1991; Scudder and Hill, 1998; Nof, 1999; Rungtusanatham, 1998; Rungtusanatham et al., 2003), we planned the empirical aspect of the research so that the information we needed to test our theories should come from a survey conducted amongst our reference population. We kept closely to the strict recommendations given by Filippini (1997) and Hensley (1999) for fulfilling the prerequisites of reliability and validity. We also took pains to maintain the unit of analysis through the triangulation of data sources and the analytical rigor and statistical control of the techniques used. In short, following in the footsteps of Malhotra and Grover (1998), we have tried to construct theory out of existing theory, allowing our postulated hypotheses to be a guide to empirical research and confirming results by triangulation.

\section{Population and gathering of data}

The target population comprised companies in the Andalusian aeronautical sector, including three plants belonging to the CASA Group, and 17 small and medium-size ancillary companies. Given the size of the population, it was decided to conduct a comprehensive analysis of the sector and study the population in its entirety.

This study is part of a project of a much wider scope which would require the use of quite long questionnaires. We therefore decided to split the survey into two parts in order to overcome any anticipated initial respondent resistance to a single, over-long questionnaire. Initially, a postal survey was used, designed to determine the types of AMT used in the sector and the extent to which they had been implemented, the responses being completed on 10 March 2000. There was a 100 percent response rate due to intense follow-up telephone work, which not only meant this nonetheless prolonged delay was shortened, but also enabled us clear up doubts that were had in some plants about some of the questions. This helped to ensure greater reliability of the data obtained.

A second questionnaire was designed to obtain data on the investment adoption and implementation process, including questions directly related to this paper involving, for the main part, the importance each company gives to the various competitive priorities in operations (costs, quality, delivery and flexibility) as an approach to its operations strategy, as well as the indicators used to measure the performance of investments in AMT and the use that the plants admit they make of the different

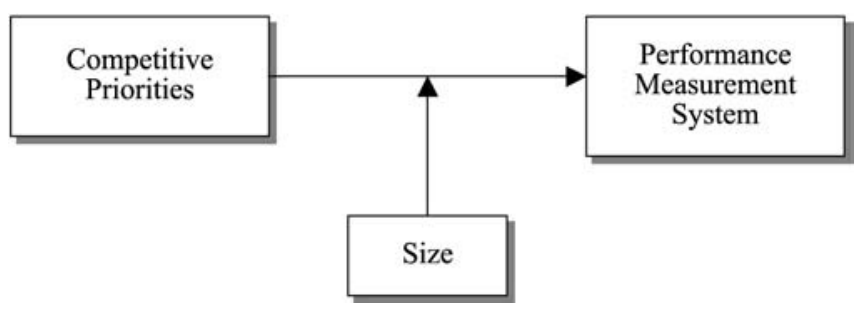

Figure 1. Theoretical model 
indicators for the different functional areas. The content of the questionnaire related to those questions is incorporated below in its entirety within Tables I, II and III. We decided to conduct personal interviews to complete this second questionnaire so as to prevent another long delay in the collation of survey responses, and also to avoid any further possible problems of interpretation of the questions, both of which were possible due to the relative complexity of the second questionnaire. The second questionnaire was sent out to the plants on 24 January 2001, to allow respondents to familiarize themselves with its content well before the interview. On this occasion, the process of data gathering took less than three months.

It was the managing director and owner who completed both questionnaires in most of the smaller ancillary companies; when mail is the only means of contact for this type of study, advantages of this kind cannot usually be guaranteed. It was the head or assistant head of engineering in the larger plants who completed the first questionnaire and attended the interviews.

\section{Measurement of variables and data analysis}

Interviewees were asked to tick from an open list of performance measures all those that had been used to monitor the performance of their investments in AMT (those indicators can be seen below in Table III, in the results section). In addition, they were asked to indicate, as a percentage, the relative importance given to each area (commercial, accounts/finance, technical/operational or other) when assessing the performance of installed AMT. As the second objective of our study was to compare the investment performance indicators with the investment objectives, the companies were provided with a list of possible performance indicators that, in short, covered all the usual indicators for competitive priorities (see Table I), with a view to determining

Table I.

Some factors that could motivate investments (indicators of competitive priorities)

\begin{tabular}{ll}
\hline & \\
\hline Costs & Corbett (1996); Roth (1996) \\
Inventory reduction & \\
Increase in utilization of capacity & \\
$\begin{array}{l}\text { Reduce production costs } \\
\text { Increase in labor productivity }\end{array}$ & \\
Quality & Boyer and McDermott (1999); Avella and \\
To offer high performance products & Fernández (2000) \\
Consistent quality with low defect rate & \\
To offer reliable products & Boyer and Pagell (2000); Ward and Duray (2000) \\
Deliveries & \\
Reduction of lead times & \\
Fast deliveries & Joshi et al. (2003); Vastag and Whybark (2003) \\
Meet promised delivery times & \\
Flexibility & \\
Fast introduction of new products & \\
Fast changes in design & \\
Adjust capacity quickly & \\
Fast volume changes & \\
Offering a wide variety of products & \\
Fast changes in product mix & \\
\hline
\end{tabular}




\begin{tabular}{|c|c|c|c|c|c|c|c|c|c|}
\hline Descriptive & \multicolumn{2}{|c|}{$\begin{array}{l}\text { Commercial } \\
\text { area } \\
\text { (Value) }\end{array}$} & \multicolumn{2}{|c|}{$\begin{array}{c}\text { Accounts/ } \\
\text { finances area } \\
\text { (Value) }\end{array}$} & \multicolumn{2}{|c|}{$\begin{array}{c}\text { Technical/ } \\
\text { operational area } \\
\text { (Value) }\end{array}$} & \multicolumn{2}{|c|}{$\begin{array}{c}\text { Other areas } \\
\text { (Value) }\end{array}$} & \\
\hline Average & \multicolumn{2}{|c|}{26.94} & \multicolumn{2}{|c|}{5.83} & \multicolumn{2}{|c|}{66.67} & \multicolumn{2}{|c|}{0.55} & \\
\hline Typical & \multirow{3}{*}{\multicolumn{2}{|c|}{$\begin{array}{r}14.87 \\
0.00\end{array}$}} & & & & & & & \\
\hline deviation & & & \multicolumn{2}{|c|}{10.32} & \multicolumn{2}{|c|}{14.14} & \multicolumn{2}{|c|}{2.36} & \\
\hline Minimum & & & & & & & & & \\
\hline Maximum & \multicolumn{2}{|c|}{50.00} & & & \multicolumn{2}{|c|}{90.00} & \multicolumn{2}{|c|}{10.00} & \\
\hline Importance of & & & & & & & & & \\
\hline criterion & Freq. & $\%$ & Freq. & $\%$ & Freq. & $\%$ & Freq. & $\%$ & \\
\hline $0 \%$ & 2 & 11.1 & 13 & 72.2 & 0 & 0.0 & 17 & 94.4 & \\
\hline From 1 to $25 \%$ & 6 & 33.3 & 4 & 22.2 & 0 & 0.0 & 1 & 5.6 & Table II. \\
\hline From 26 to $50 \%$ & 10 & 55.6 & 1 & 5.6 & 5 & 27.8 & 0 & 0.0 & Relative importance of \\
\hline From 51 a $75 \%$ & 0 & 0.0 & 0 & 0.0 & 7 & 38.9 & 0 & 0.0 & each area in which \\
\hline From 76 to $99 \%$ & 0 & 0.0 & 0 & 0.0 & 6 & 33.3 & 0 & 0.0 & investment performance \\
\hline $100 \%$ & 0 & 0.0 & 0 & 0.0 & 0 & $0.0 \%$ & 0 & 0.0 & is to be measured \\
\hline
\end{tabular}

\begin{tabular}{|c|c|c|c|c|c|c|c|}
\hline \multirow[b]{2}{*}{ Performance measures } & \multicolumn{2}{|c|}{$\begin{array}{c}\text { Design AMT } \\
(n=16)\end{array}$} & \multicolumn{2}{|c|}{$\begin{array}{l}\text { Manufacturing } \\
\text { AMT }(n=15)\end{array}$} & \multicolumn{2}{|c|}{$\begin{array}{l}\text { Planning AMT } \\
\quad(n=13)\end{array}$} & \\
\hline & Freq. & $\%$ & Freq. & $\%$ & Freq. & $\%$ & \\
\hline Speed of delivery & 4 & 25.0 & 2 & 13.3 & 3 & 23.1 & \\
\hline Meeting delivery times & 14 & 87.5 & 13 & 86.7 & 13 & 100.0 & \\
\hline Customer complaints & 7 & 43.8 & 6 & 40.0 & 5 & 38.5 & \\
\hline Pay back & 5 & 25.0 & 6 & 40.0 & 3 & 23.1 & \\
\hline Returns on investment (ROI) & 1 & 6.3 & 0 & 0.0 & 0 & 0.0 & \\
\hline Capital value & 3 & 18.8 & 3 & 20.0 & 3 & 23.1 & \\
\hline Return rate & 3 & 18.8 & 3 & 20.0 & 3 & 23.1 & \\
\hline Inventory reduction & 2 & 12.5 & 1 & 6.7 & 2 & 15.4 & \\
\hline Increase in utilization of capacity & 12 & 75.0 & 15 & 100.0 & 12 & 92.3 & \\
\hline Increase in labor productivity & 10 & 62.5 & 13 & 86.7 & 9 & 69.2 & \\
\hline Defect rate & 10 & 62.5 & 14 & 93.3 & 11 & 84.6 & \\
\hline Product quality & 11 & 68.8 & 14 & 93.3 & 9 & 69.2 & \\
\hline Lead times & 8 & 50.0 & 10 & 66.7 & 10 & 76.9 & \\
\hline Speed of changes in designs & 7 & 43.8 & 3 & 20. & 3 & 23.1 & \\
\hline Speed of capacity adjustments & 5 & 31.3 & 9 & 60.0 & 6 & 46.2 & \\
\hline Speed of changes in volume of production & 6 & 37.5 & 8 & 53.3 & 6 & 46.2 & \\
\hline Variety of products & 7 & 35.0 & 9 & 60.0 & 7 & 53.8 & Table III. \\
\hline Speed of changes in product mix & 3 & 18.8 & 4 & 26.7 & 4 & 30.8 & Degree to which different \\
\hline Frequency of maintenance & - & - & 2 & 13.3 & - & - & indicators are used to \\
\hline Motivation of personnel & - & - & 1 & 6.7 & - & - & measure performance \\
\hline
\end{tabular}

the correspondence between them. The interviewees were also provided with the opportunity to note down any other indicator they wished. All were measured with a dichotomized variable with values of 1 (if the indicator was used in the company) and 0 (if not). Aforesaid indicators were grouped together in three areas, in line with Small and Chen (1995): commercial, accounts/finances and technical/operational. The relative importance that the interviewees gave to each of these areas was also measured, and 
they were asked to assign a percentage to each in such a way that the sum total was 100 percent.

As has been indicated, the objectives that motivated the investments were determined by the indicators that are habitually taken into consideration when competitive priorities are being identified (i.e. costs, quality, delivery and flexibility). These are set out in Table I. Nevertheless, the possibility was also left open for the interviewees to add any other motive that was not already specified. From the very first interview it could be seen that the companies did not have very clear ideas about the objectives behind the investments. There was neither an explicit technological strategy, nor the corresponding explicit operations strategy. As a result, we opted for asking the interviewees to indicate the three main objectives that had motivated the investment for each type of AMT from a list of objectives they had been provided with (as seen in Table IV). Then we again used a dichotomized variable with values of 1 (if the objective in question had been the motive for the investment) and 0 (if the opposite were true). The relative importance that was given to each competitive priority in their companies in the opinion of the interviewees was also measured by assigning a percentage to each in such a way that the sum total was 100 percent.

As has already been stated, the various advantages associated with the different types of AMT could give rise to a number of different technological and operations strategies, with the result that a variety of competitive priorities and a range of systems for measuring the performance of said investments might also occur. On this basis, all the questions were repeated for the three types of AMT (see Table V) that are usually distinguished according to their function or type of activity: design, manufacturing and planning, in accordance with the criteria most widely-used in research (Boyer and Pagell, 2000; Kotha and Swamidass, 2000).

Finally, in the case of the company size variable, we preferred to estimate it on the basis of annual sales volumes, given that one of the possible effects of investing in AMT that can be predicted might be a variation in the size of the work-force. Table VI shows plant distribution in the population by size.

Once the required information had been gathered it was formally analysed. Various statistics were used to test the working hypotheses depending on the nature of the variables involved in each case. On the one hand, a Student's $t$-test was applied to related samples to test the first hypothesis regarding the relative importance of each area of performance. On the other hand, the second hypothesis, which deals with the correspondence there might be between objectives that motivated investments, as being representative of the existence of an operations strategy, and the performance measurements used, has been tested with Fisher's exact statistic test, given the qualitative character of both variables. To test the third hypothesis, Pearson's

Table IV.

Specificity of indicators for measuring the performance of AMT investment projects

Issue

Answer Yes (\%)

Answer No (\%)

The techniques used for measuring the performance

of investments in AMT:

$\ldots$ are different from those used for other types of investments

... differ in accordance with the type of AMT in question

5.3

26.3
94.7

73.7 


\section{Sources}

Design AMT

Computer-aided design (CAD)

Computer-aided engineering

Computer-aided process planning (CAPP)

Group technology (GT)

Manufacturing AMT

Computer-aided manufacturing (CAM)

Numerical control (NC)

Computerized numerical control (CNC)

Industrial robots

Automated guided vehicles (AGV)

Automated storage and retrieval systems (AS/RS)

Flexible manufacturing systems (FMS)

Computer-aided inspection (CAI)

Planning AMT

Materials requirements planning (MRP)

Manufacturing resources planning (MRPII)

Just in time (JIT)

Computerized preventive maintenance (CPM)

Activity-based costing $(\mathrm{ABC})$

Shopfloor control (SFC)
Rosenthal (1984); Meredith (1987); Adler (1988)

Lei and Goldhar (1991); Gerwin and Kolodny

(1992); Saraph and Sebastian (1992); Machuca et al.

(1995); Boyer et al. (1996); Cohen and Apte (1997)
Swamidass and Kotha (1998); Kotha and

Swamidass (2000); Boyer and Pagell (2000)
Table V.

Advanced manufacturing technologies per type of activity

\begin{tabular}{|c|c|c|c|c|c|c|}
\hline Sales (€) & Plants & Percentage & Employees & Plants & Percentage & \\
\hline From 300 to 3,000 & 11 & 55 & From 1 to 50 & 8 & 40 & \\
\hline From 3,001 to 6,000 & 3 & 15 & From 51 to 100 & 7 & 35 & \\
\hline From 6,001 to 30,000 & 3 & 15 & From 101 to 150 & 2 & 10 & \\
\hline From 30,001 to 90,000 & 1 & 5 & More than 700 & 3 & 15 & \\
\hline More than 90,000 & 2 & 10 & & & & Table VI. \\
\hline Minimum & 60 & & Minimum & 14 & & Plants in the population \\
\hline Maximum & 22,000 & & Maximum & 1,135 & & by size \\
\hline
\end{tabular}

correlation coefficient was used to analyze the influence size has on the possible fit between the objectives of the investments and their performance measurement. In this regard, it is important to highlight that all the statistical tests that were conducted take into account the size of the sample when determining the significance of the contrast. The tests are therefore still valid despite being calculated on the basis of a relatively small number of elements. The SPSS 10.0 statistical program was used for data analysis.

\section{Results}

Functional areas and performance measurements: descriptive analysis

Table IV shows the results related to the techniques or indicators used to measure AMT investment performance. It can be stated in the first instance that the performance measures used to monitor investments in AMT do not differ to any great degree from those used in the case of more traditional projects; only a single company 
out of the 19 in the population using AMT of one kind or another stated that performance indicators differed from those used to measure other investments. As for the question of whether different performance measures were used depending on the type of AMT, the answer was affirmative in five cases, that is, in over 25 percent of AMT user companies. Nonetheless, these five companies do not share a similar profile either in respect of size or type of activity, nor with regard to the AMT they have invested in.

We shall refer to the data shown in Table II for the analysis of the relative importance given to each of the functional areas for which performance has to be measured, which is the second issue included in the first working hypothesis. As can be seen in the table, the average importance given to the technical/operational area is considerably higher than for the remaining areas (66.67 percent); it is followed, in order of importance, by the commercial area, with an average relative importance approaching 27 percent - i.e. 40 percentage points below the technical/operational area - with the accounts/finances area in third place, with an average of 5.83 percent. This indicates that in the Andalusian aeronautical sector, non-financial measurement of the quality, delivery performance and flexibility not only supplement financial indicators, but even exceed them in importance, in keeping with the latest works on the subject

(De Toni and Tonchia, 2001). The clear differences in the relative importance of each of the functional areas whose performance is measured can also be appreciated if it is noted that the minimum importance given to the technical/operational area is 40 percent, and that over 70 percent of the companies consider that it rates an importance of over 50 percent; at the same time, a similar number of companies give a zero relative importance to the area of accounts/finances, while over half the companies give a relative importance of between 26 percent-50 percent to the commercial area.

Table III shows the degree of use of the different performance indicators. At least two circumstances can be highlighted. On the one hand, totally in keeping with the conclusion from the analysis of Table II, technical-operational measures are the most widely-used - especially those listed from the increase in use of capacity, to product quality (all can be found in over 60 percent of the users who measure the performance of their investments) - on the other hand, the differences between the performance measures used depending on the type of AMT are minimal, there being a similar percentage distribution for the three types and for each measure.

\section{Testing of hypotheses}

Although the data in Table II commented on above suggests that the differences in the importance given to the different areas for performance measurement are quite clear, the Student's $t$-test was performed on related samples to confirm that said differences are, in fact, significant and that, as such, we can accept the first of our hypotheses. Table VII shows the results of said test with the significance (in italic type) of the differences found between all pairs considered per area of performance for a $p$-level $=0.01$.

The second working hypothesis deals with the similarities or differences that can be found between performance indicators and investment objectives. By testing the hypothesis, we shall attempt to see whether, as would appear logical, companies use the objectives that motivated investments in AMT as AMT investment performance indicators. Although ultimately all the objectives are inter-related, as a result of which a specific performance measurement could be considered as indicative of various 
objectives, albeit indirectly, Fisher's exact statistic was obtained and applied to coinciding pairs of objectives and performance indicators, (as a result of which, only those items that had been mentioned as objectives that motivated investments and as a indicator of performance were taken into account). No significant relationships were found between any of the objectives that motivated the investment and their corresponding performance measure.

The findings lead us to reject our hypothesis and to accept that there is no correspondence between the objectives pursued with the investment, that is, between each company's hypothetical operations strategy, and the performance measures used. We could be forgiven for thinking, therefore, that we are again witness to the fact that there is no awareness in the sector that performance measurement should be guided by the objectives the company's strategic operations are based on.

The explanation for this could be attributed to the fact that vision and strategic planning are not the strong-points of SMEs, which the majority of the plants analysed are, as is suggested by the third of our hypotheses. In order to validate our conjecture we have conducted a dual correlation analysis: between size and the importance given to each area by which performance is to be measured, the results of which can be seen in Table VIII, and between size and the importance of the various competitive priorities, the results of which can be found in Table IX.

\begin{tabular}{lrcc}
\hline Pair of variables & \multicolumn{1}{c}{$t$} & $\mathrm{df}$ & Sig. (bilateral) \\
\hline Commercial/accounts-finances & 4.187 & 17 & 0.001 \\
Commercial/technical-operational & -6.209 & 17 & 0.000 \\
Commercial/other & 7.498 & 17 & 0.000 \\
Accounts-finances/technical-operational & -13.186 & 17 & 0.000 \\
Accounts-finances/other & 2.052 & 17 & 0.000 \\
Technical-operational/other & 19.201 & 17 & 0.000
\end{tabular}

Table VII.

Students' $t$-test of related samples on importance of each performance area

\begin{tabular}{|c|c|c|}
\hline & Annual sales & \\
\hline \multicolumn{3}{|l|}{ Commercial area } \\
\hline Pearson's correlation & -0.665 & \\
\hline Sig. (bilateral) & 0.003 & \\
\hline$n$ & 18 & \\
\hline \multicolumn{3}{|l|}{ Accounts-finances area } \\
\hline Pearson's correlation & 0.455 & \\
\hline Sig. (bilateral) & 0.058 & \\
\hline$n$ & 18 & \\
\hline \multicolumn{3}{|l|}{ Technical-operational area } \\
\hline Pearson's correlation & 0.385 & \\
\hline Sig. (bilateral) & 0.115 & \\
\hline$n$ & 18 & Table VIII. \\
\hline Other areas & & Correlation analysis \\
\hline Pearson's correlation & -0.106 & between size of company \\
\hline Sig. (bilateral) & 0.675 & and importance of each \\
\hline$n$ & 18 & area of performance \\
\hline
\end{tabular}


Table IX.

Correlation analysis between size of business and importance given to each strategic objective

\begin{tabular}{lc}
\hline & Annual sales \\
\hline Importance of costs objective & \\
Pearson's correlation & -0.143 \\
Sig. (bilateral) & 0.572 \\
$n$ & 18 \\
Importance of quality objective & \\
Pearson's correlation & -0.211 \\
Sig. (bilateral) & 0.401 \\
$n$ & 18 \\
Importance of delivery objective & 0.468 \\
Pearson's correlation & 0.050 \\
Sig. (bilateral) & 18 \\
$n$ & \\
Importance of flexibility objective & -0.322 \\
Pearson's correlation & 0.193 \\
Sig. (bilateral) & 18 \\
$n$ & \\
\hline
\end{tabular}

It can be seen in Table VIII that correlation is significant for the commercial area, and it can be stated that the size of the company significantly influences the relative importance given to the commercial area in measuring AMT investment performance. It can also be seen that smaller companies (negative Pearson correlation coefficient $(-0.665))$ are those that give greater importance to these indicators. If it is the smaller companies that put greater emphasis on performance measurement for commercial aspects, for which they use information regarding meeting delivery-times, it should be these same companies that give greater importance to the strategic priority of meeting delivery-times, in keeping with our previously-stated assumption that a good performance measurement system should reflect the strategic priorities of the business unit (Leong and Ward, 1995, amongst others). Table IX shows the results of the corresponding correlation analysis that was performed not only for the objectives of delivery, but for all four that were considered: costs, quality, delivery and flexibility. Companies that did not respond to questions on performance measurement were eliminated, because they either had not made any investments in AMT, or because they stated they did not carry out performance measurement of any kind. It can be seen that there is no significant correlation between the size of the company and the relative importance given to each strategic objective in operations, although there is one correlation that is on the limit, with a 0.050 significance. This is precisely the significance between size and the importance of the delivery objective. However, the Pearson correlation coefficient is positive in this case (0.468), which indicates that larger companies tend to give more relative weight to delivery rather than other strategic objectives.

To summarize, the information gained from the data analysis is that smaller companies use more delivery-time indicators, which is representative of their concern for commercial issues, even though they give no special priority to any competitive objective for operations. That is, they do not recognize operations objectives specifically linked to any AMT acquisitions they may have made, but they do understand that it should be their commercial competition indicators that will be of greater use to them as they check on how said acquisitions are functioning. For their 
part, the larger plants have shown that they appear to have clearer competitive priorities, to be specific, reliable delivery, although they do not make any special use of the related delivery-time indicators to assess investment performance. The data therefore does not endorse the role played by size as a contextual feature that influences the fit between objectives and performance indicators.

\section{Discussion and conclusions}

There is currently a large group of heads of operations who are faced with the problem of how to exploit AMT in such a way as eke out maximum benefit. One of the reasons why it is hard to determine whether said benefit has been achieved or not can be found in the traditional focus used for performance measurement, which lends excessive importance to financial measurement. With this study it is our intention to provide new evidence on the adaptation of the make up and combination of the type of performance measures currently used by plants in the aeronautical industry, one of the sectors in which technological innovation is of utmost importance. Our second objective was focused on testing whether there is any correspondence between said measures and the areas where performance is measured, and the objectives that motivate investments, as theory on the subject recommends there should be, and whether this correspondence is influenced by the size of the plant.

The analysis has allowed us to see, firstly, that the performance measures that are used to monitor AMT investment projects differ only slightly from those used to evaluate more traditional investments, and that only just over a quarter of users claim to use different measurement systems depending on the type of AMT, although it has not been possible to establish a common profile for these plants with respect to their size, investments in AMT or type of activity. This finding is, on its own, interesting, as it indicates that companies in the aeronautical sector, which is so strongly linked to the new technologies and innovation, in general terms, have not kept themselves abreast of how their investments in new technologies should be assessed. This time-lag could be due to a number of causes. One reason could be that they were extremely up to date prior to contending with AMT and as such had already developed new ways of measuring investments. In our opinion, if this were the main and sole reason, the plants analysed could have been expected to know perfectly well what benefits they might expect from taking a further step in modernising their equipment. Nonetheless, as has been pointed out in the previous pages, this is not the fact in the majority of the firms consulted. Logically, this leads us to believe that either the real reasons are linked to the contingent factors analysed in this study, or that there are other decisive factors. It is, however, interesting to discover that some plants use different ways of measuring, depending on the types of equipment that have been acquired. This confirms the findings of previous studies of other sectors, and means these companies are one jump ahead of the recommendations made in publications such as those found herein. This result is a ray of hope at least.

It has also been proved that in the sector being analysed there are significant differences in the importance given to the different areas for performance measurement, whatever the type of AMT the companies consulted had acquired. The average importance given to the operations area is considerably greater than that given to the remaining areas (66.67 percent), which implies that physical measurements of quality, delivery times and flexibility not only supplement 
financial indicators in the Andalusian aeronautical sector, but that they can even exceed them in importance. On the one hand these findings demonstrate that the situation the sector is in is, perhaps, not so disappointing as the previous paragraph might have suggested, and, on the other hand, that recommendations made in our reference works are already being taken into account by companies in a number of sectors of industry. With regard to Ghalayini and Noble (1996) and, more recently, Neely et al. (1997), a careful study of interviewees' preferred indicators in effect shows us that the measures used are not solely based on antiquated accountancy systems, nor are they mainly financial. Moreover, they can be used by all employees as they are mainly measures linked to tactical operations aspects which can be applied to a variety of technological environments. These features will allow us to characterize the measurement systems used by the plants in the population, given the lack of other information, such as non traditional systems.

The second stage of the study was aimed at identifying any possible relationships between the existence of an operations strategy and the performance measurements used to monitor the former. The data we obtained indicates that this relationship does not appear to exist. This is yet another example of the fact that there is no apparent awareness in the sector that performance measurement should be guided by the objectives that nurture company strategy. This should come as no surprise, given that vision and strategic planning are not SMEs' strong points, and this is a feature of the majority of the companies that were analysed (Machuca et al., 2004). It was this that led us to put forward our third hypothesis.

Our attempt at validating this hypothesis has brought out something of a paradox. It is the plants of a larger size (as measured by volume of annual sales) that tend to afford a greater relative weight to delivery rather than to other strategic objectives. This data indicates that the larger companies may have an operations strategy, whether tacit or explicit, in which meeting delivery times is perceived as a priority. If this is true, according to the theoretical postulations put forward at the beginning of the paper, the companies in question should be particularly inclined to use non-financial indicators related to fulfilling delivery times. The results that were obtained point in a completely opposite direction, however. As previously stated, the data do not support size as a contextual factor that influences the fit between objectives and performance indicators. However, having rejected the view that the smaller companies use performance indicators related to deliveries as a consequence of their strategy, it could be argued that they use them because they come imposed in some way by larger companies, those really concerned about deliveries as a strategic objective, and whose processes depend on the supplies of the former. If this is the case, two questions still remain: Why do not measures related to deliveries appear to be relatively more important for larger firms? Why do not SMEs appear to consider fulfilling deliveries as an especially important strategic objective?

This set of findings provides us with surprising data for a sector that, as we pointed out in the introduction, is considered to be strategic. It seems as though the companies either do not have an operations strategy, or competitive objectives. If the former does not exist, the performance measurement systems cannot be guided by it, which leads to a complex and disruptive gap between strategy and the way of measuring the results of said strategy. And yet, although some of those interviewed recognized that they do not know what the objectives that motivated investment were, at the same time they 
have developed performance measurement systems inspired by indicators for fulfilling deliveries.

In short, although several characteristics should enable us to refer to the measurement system favoured in the sector as non traditional in accordance with the recommendations in Ghalayini and Noble (1996), the fact that it is not the business strategy that serves as a guide to the AMT investment performance assessment and monitoring process leads us to classify it as the opposite, that is, as a traditional system. If this is the case, we would have to recognize that the sector of industry that was analysed has not successfully overcome the challenge it faces. Be that as it may, we believe that in the light of the findings, the question of what inspires a company's performance measurement system is still open, especially in those cases where there is no explicit strategy.

Furthermore, one issue of great importance is the determination of when the critical performance measurements and performance benchmarks should be established. For some authors (Small and Chen, 1995, amongst others), the most suitable time for establishing said criteria is during the process of strategic and financial justification of the new technology, bearing in mind that it is at this time when the departments involved can identify their expectations and make an effort to determine the period of time over which these should be achieved. If they were to do this, all the departments would be better placed to monitor the progress achieved during and after the AMT installation phase, and make the necessary adjustments to achieve the objectives that were set.

Knowledge of these issues would to a great extent help to understand how investment performance is measured in the Andalusian aeronautical sector, and also to gain a deeper understanding of the conclusions arrived at in this study. However, this would require a profound longitudinal analysis to which not all companies are prepared to devote the necessary time.

\section{Implications for management practice}

In other respects, what suggestions for practical application could be drawn from this and given to companies in the sector? Undoubtedly, as other authors previously cited throughout this study had already noted, what seems to be indispensable is an improvement in the determination of the critical variables that should be used to measure performance. For this to be done, we first have to be capable of determining more clearly the benefits that it is anticipated will result from investments, or the objectives that motivated them. Without this first prerequisite, it would seem difficult to be in a position to take into consideration other important aspects related to a company's performance measurement system, such as whether there are important gaps or false alarms, in the sense suggested by Schmenner and Vollmann (1994), the frequency with which measurement should be conducted and where the data should be sourced from (Neely et al., 1997), and the frequency with which these measures should be replaced or supplemented with new measures in order that they do not lose purpose or validity (Waggoner et al., 1999).

\section{Limitations}

Finally, if it is accepted that the data that were collected are accurate thanks to the steps that were taken to prevent certain factors, such as, the degree to which it could be 
easily understood or the level of attention of the interviewee, for example, affecting it, then, the findings should be highly explanatory for the population. Nevertheless, it would not in principle be correct to consider extrapolating the results to any other sample or population, and the statistical analysis was never intended to be inferred in a general way. It could be said that this contribution relies, rather, on the possibility of a logical extrapolation to circumstances where the findings might apply, and researchers can judge whether the particular findings would be valid.

\section{References}

Abernethy, M.A. and Lillis, A.M. (1995), "The impact of manufacturing flexibility on management control system design", Accounting, Organizations and Society, Vol. 20 No. 4, pp. 241-58.

Bhimani, A. (1994), "Monitoring performance measures in UK manufacturing companies", Management Accounting, January, pp. 34-6, 54.

Bititci, U.S., Carrie, A.S. and McDevitt, L. (1997), "Integrated performance measurement systems: a development guide", International Journal of Operations \& Production Management, Vol. 17 No. 5, pp. 522-34.

Bititci, U.S., Suwignjo, P. and Carrie, A.S. (2001), "Strategy management through quantitative modelling of performance measurement systems", International Journal of Production Economics, Vol. 69, pp. 15-22.

Boyer, K.K. and McDermott, C. (1999), "Strategic consensus in operations strategy", Journal of Operations Management, Vol. 17 No. 3, pp. 289-305.

Boyer, K.K. and Pagell, M. (2000), "Measurement issues in empirical research: improving measures of operations strategy and advanced manufacturing technology", Journal of Operations Management, Vol. 18 No. 3, pp. 361-74.

Boyer, K.K., Ward, P.T. and Leong, G.K. (1996), "Approaches to the factory of the future: an empirical taxonomy”, Journal of Operations Management, Vol. 14 No. 4, pp. 297-313.

Brown, D.M. and Laverick, S. (1994), "Measuring corporate performance", Long Range Planning, Vol. 27 No. 4, pp. 89-98.

Buffa, E.S. (1980), "Research in operations management", Journal of Operations Management, Vol. 1 No. 1, pp. 1-8.

Chase, R.B. (1980), "A classification and evaluation of research in operations management", Journal of Operations Management, Vol. 1 No. 1, pp. 9-14.

Chiadamrong, N. and O'Brien, C.O. (1999), "Decision support tool for justifying alternative manufacturing and production control systems", International Journal of Production Economics, Vol. 60-61, pp. 177-86.

Cohen, M.A. and Apte, U.M. (1997), Manufacturing Automation, McGraw-Hill, New York, NY.

Corbett, L.M. (1996), "A comparative study of the operations strategies of globally- and domestically-oriented New Zealand manufacturing firms", International Journal of Production Research, Vol. 34 No. 10, pp. 2677-89.

Daniels, R.C. and Burns, N.D. (1997), "Behavioural consequences of performance measures in cellular manufacturing”, International Journal of Operations \& Production Management, Vol. 17 No. 11, pp. 1066-80.

De Toni, A. and Tonchia, S. (2001), "Performance measurement systems: models, characteristics and measures", International Journal of Operations \& Production Management, Vol. 21 Nos 1/2, pp. 46-70. 
Del Sol, P. and Ghemawat, P. (1999), "Strategic valuation of investment under competition", Interfaces, Vol. 29 No. 6, pp. 42-56.

Dominguez Machuca, J.A., Álvarez Gil, M.J., García González, S., Domínguez Machuca, M.A. and Ruiz Jiménez, A. (1995), Dirección de Operaciones: Aspectos Estratégicos en la Producción y los Servicios, McGraw-Hill, Madrid.

Dominguez Machuca, J.A., Sacristán Díaz, M. and Álvarez Gil, M.J. (2004), “Adopting and implementing advanced manufacturing technology: new data on key factors from the aeronautical industry", International Journal of Production Research, Vol. 42 No. 16, pp. 3183-202.

Filippini, R. (1997), “Operations management research: some reflections on evolution, models and empirical studies in OM", International Journal of Operations \& Production Management, Vol. 17 No. 7, pp. 55-670.

Gerwin, D. and Kolodny, H. (1992), Management of Advanced Manufacturing Technology: Strategy, Organization \& Innovation, John Wiley \& Sons, New York, NY.

Ghalayini, A.M. and Noble, J.S. (1996), "The changing basis of performance measurement", International Journal of Operations \& Production Management, Vol. 16 No. 8, pp. 63-80.

Hensley, R.L. (1999), "A review of operations management studies using scale development techniques”, Journal of Operations Management, Vol. 17 No. 3, pp. 343-58.

Joshi, M.P., Kathuria, R. and Porth, S.J. (2003), "Alignment of strategic priorities and performance: an integration of operations and strategic management perspectives", Journal of Operations Management, Vol. 21 No. 3, pp. 353-69.

Kakati, M. (1997), "Strategic evaluation of advanced manufacturing technology", International Journal of Production Economics, Vol. 53 No. 2, pp. 141-56.

Kaplan, R.S. (1986), "Must CIM be justified by faith alone?", Harvard Business Review, Vol. 64 No. 2, pp. 87-93.

Kaplan, R.S. and Norton, D.P. (1992), "The balanced scorecard - measures that drive performance", Harvard Business Review, Vol. 70 No. 1, pp. 71-9.

Karsak, E. and Tolga, E. (2001), "Fuzzy multi-criteria decision-making procedure for evaluating advanced manufacturing system investments", International Journal of Production Economics, Vol. 69 No. 1, pp. 49-64.

Keegan, D.P., Eiler, R.G. and Jones, C.R. (1989), “Are your performance measures obsolete?”, Management Accounting, Vol. 70 No. 12, pp. 45-50.

Kotha, S. and Swamidass, P.M. (2000), "Strategy, advanced manufacturing technology and performance: empirical evidence from US manufacturing firms", Journal of Operations Management, Vol. 18 No. 3, pp. 257-77.

Lei, D. and Goldhar, J.D. (1991), "Computer-integrated manufacturing (CIM): redefining the manufacturing firm into a global service business", International Journal of Operations \& Production Management, Vol. 11 No. 10, pp. 5-18.

Leong, G.K. and Ward, P.T. (1995), "The six Ps of manufacturing strategy”, International Journal of Operations \& Production Management, Vol. 15 No. 12, pp. 32-45.

MacDougall, S.L. and Pike, R.H. (2003), "Consider your options: changes to strategic value during implementation of advanced manufacturing technology", OMEGA: The International Journal of Management Science, Vol. 31 No. 1, pp. 1-15.

Malhotra, M.K. and Grover, V. (1998), "An assessment of survey research in POM: from constructs to theory", Journal of Operations Management, Vol. 16 No. 4, pp. 407-25.

Meredith, J.R. (1987), "The strategic advantages of the factory of the future", California Management Review, Vol. 29 No. 3, pp. 27-41. 
Meredith, J.R. and Suresh, N.C. (1986), "Justification techniques for advanced manufacturing technologies", International Journal of Production Research, Vol. 24 No. 5, pp. 1043-57.

Morgan, L.O. and Daniels, R.L. (2001), "Integrating product mix and technology adoption decisions: a portfolio approach to adoption of advanced manufacturing technologies in the automobile industry", Journal of Operations Management, Vol. 19 No. 2, pp. 219-38.

Neely, A., Mills, J., Platts, K., Gregory, M. and Richards, H. (1994), "Realizing strategy through measurement", International Journal of Operations \& Production Management, Vol. 14 No. 3, pp. 140-52.

Neely, A., Richards, H., Mills, J., Platts, K. and Bourne, M. (1997), "Designing performance measures: a structured approach", International Journal of Operations \& Production Management, Vol. 17 No. 11, pp. 1131-52.

Nof, S.Y. (1999), "Next generation of production research: wisdom, collaboration, and society", International Journal of Production Economics, Vol. 60-61, pp. 29-34.

Pawar, K.S. and Driva, H. (1999), "Performance measurement for product design and development in a manufacturing environment", International Journal of Production Economics, Vol. 60-61, pp. 61-8.

Perera, S., Harrison, G. and Poole, M. (1997), “Customer-focused manufacturing strategy and the use of operations-based non-financial performance measures: a research note", Accounting Organizations and Society, Vol. 22 No. 6, pp. 557-72.

Rosenthal, L. (1984), "Progress toward the "factory of the future", Journal of Operations Management, Vol. 4 No. 3, pp. 203-29.

Roth, A.V. (1996), "Neo-operations strategy: linking capabilities-based competition to technology”, in Gaynor, G.H. (Ed.), Handbook of Technology Management, McGraw-Hill, New York, NY, pp. 38.1-38.44.

Rungtusanatham, M.J. (1998), "Let us not overlook content validity”, Decision Line, Vol. 29 No. 4, pp. 10-13.

Rungtusanatham, M.J., Choi, T.Y., Hollingworth, D.G., Wu, Z. and Forza, C. (2003), "Survey research in operations management: historical analyses", Journal of Operations Management, Vol. 21 No. 4, pp. 475-88.

Saraph, J.V. and Sebastian, R.J. (1992), "Human resource strategies for effective introduction of advanced manufacturing technologies (AMT)", Production and Inventory Management Journal, Vol. 33 No. 1, pp. 64-70.

Schmenner, R.W. and Vollmann, T.E. (1994), "Performance measures: gaps, false alarms and the "usual suspects", International Journal of Operations \& Production Management, Vol. 14 No. 12 , pp. 58-69.

Scudder, G.D. and Hill, C.A. (1998), "A review and classification of empirical research in operations management”, Journal of Operations Management, Vol. 16 No. 1, pp. 91-101.

Shank, J.K. (1996), "Analysing technology investments - from NPV to strategic cost management (SCM)", Management Accounting Research, Vol. 7 No. 2, pp. 185-97.

Shank, J.K. and Govindarajan, V. (1992), "Strategic cost analysis of technological investments", Sloan Management Review, Vol. 34 No. 1, pp. 39-51.

Small, M.H. and Chen, I.J. (1995), "Investment justification of advanced manufacturing technology: an empirical analysis", Journal of Engineering and Technology Management, Vol. 12 Nos 1-2, pp. 27-55.

Soni, R.G., Parsaei, H.R. and Liles, D.H. (1992), "Economic and financial justification methods for advanced automated manufacturing: an overview", in Parsaei, H.R. and Mital, A. (Eds), Economics of Advanced Manufacturing Systems, Chapman \& Hall, New York, NY, pp. 3-19. 
Swamidass, P.M. (1991), "Empirical science: new frontier in operations management research", Academy of Management Review, Vol. 16 No. 4, pp. 793-814.

Swamidass, P.M. and Kotha, S. (1998), "Explaining manufacturing technology use, firm size and performance using a multidimensional view of technology", Journal of Operations Management, Vol. 17 No. 1, pp. 23-37.

Talluri, S. and Yoon, K.P. (2000), "A cone-ratio approach for AMT justification”, International Journal of Production Economics, Vol. 66 No. 2, pp. 119-29.

Tayles, M. and Drury, C. (1994), "New manufacturing technologies and management accounting systems: some evidence of the perceptions of UK management accounting practitioners", International Journal of Production Economics, Vol. 36 No. 1, pp. 1-17.

Vastag, G. and Whybark, D.C. (2003), "Is anybody listening? An investigation into popular advice and actual practices", International Journal of Production Economics, Vol. 81-82, pp. 115-28.

Waggoner, D.B., Neely, A.D. and Kennerley, M.P. (1999), "The forces that shape organisational performance measurement systems: an interdisciplinary review", International Journal of Productions Economics, Vol. 60-61, pp. 53-60.

Ward, P.T. and Duray, R. (2000), "Manufacturing strategy in context: environment, competitive strategy and manufacturing strategy", Journal of Operations Management, Vol. 18 No. 2, pp. 123-38.

Westra, D., Srikanth, M.L. and Kane, M. (1996), "Measuring operational performance in a through-put world”, Management Accounting, April, pp. 41-7.

\section{Further reading}

Adler, P.S. (1986), "New technologies, new skills”, California Management Review, Vol. 29 No. 1, pp. 9-28.

Avella Camarero, L. and Fernández Sánchez, E. (2000), "Does manufacturing determine firms' competitiveness? Evidence in a sample of Spanish industrial companies", in Dominguez Machuca, J.A. and Mandakovic, T. (Eds), Proceedings of the 1st World Conference on Production and Operations Management: POM Facing the New Millennium, Seville, (CD-ROM).

Mechling, G.W., Pearce, J.W. and Busbin, J.W. (1995), "Exploiting AMT in small manufacturing firms for global competitiveness", International Journal of Operations \& Production Management, Vol. 15 No. 2, pp. 1-76.

Miller, J.G. and Roth, A.V. (1994), "A taxonomy of manufacturing strategies", Management Science, Vol. 40 No. 3, pp. 285-304.

Milling, P.M. (1997), "Computer-integrated manufacturing in German industry: aspirations and achievements", International Journal of Operations \& Production Management, Vol. 17 No. 10, pp. 1034-45.

Neely, A., Gregory, M. and Platts, K. (1995), "Performance measurement system design", International Journal of Operations \& Production Management, Vol. 15 No. 4, pp. 80-116. 